\title{
Explore the Intention of Medical Personnel to Participate in the Home-Based Reablement Services
}

\author{
Kuo-Chung Huang \\ Professor \\ Department of Business Administration \\ Nanhua University, Chiayi, Taiwan \\ Yu-Che Yang \\ Ph.D. Student \\ Department of Business Administration \\ Nanhua University, Chiayi, Taiwan
}

\begin{abstract}
This study applies the theory of planned behavior to investigate the intention of medical personnel to participate in the home-based reablement services. Altogether 101 valid data was collected in this study. Empirical results revealed that the corporate social responsibility, attitude, subjective norm, and perceived behavioral control have respectively positive effect on their intention. Perceived behavioral control has the most significant impact on intention. Attitude has a partial mediation effect on the corporate social responsibility to the intention and subjective norm to the intention. Perceived behavioral control has a partial mediation effect on subjective norm to the intention. Through the optimal home-based reablement services plans, pre-employment training, reduce the barriers of participate and affirming the contribution of medical personnel to residents reported by the mass media can help to increase the professional ability, positive attitude, perception of corporate social responsibility and intention of the medical personnel to participate in the services.
\end{abstract}

Keywords: Home-Based Reablement Services, Theory of Planned Behavior, Corporate Social Responsibility.

\section{Introduction}

As the phenomenon of declining birthrate in Taiwan is becoming more and more serious, the overall population structure is rapidly becoming aging. According to the statistical report by Department of Household Registration, Ministry of the Interior in Taiwan (2019) show that the birthrate from 15.50\% (1995) to 7.56\% (2018), the proportion of people living in Taiwan was over 65 years old as rose from $7.63 \%$ (1995) to $14.56 \%$ (2018). Traditionally in Taiwan, when the people cannot success in their activities of daily living cause by the aging, diseases, accidents, heredity or other issues, they often face two choices to stay in their familiar home or to live in long-term care facilities. There is no doubt that to stay in the familiar home is the first choice. However, their family members always suffer a considerable burden of care from the physiological, psychological or economic when their family member with disability. In traditional large family structure, the residents with disability can be aged in the place because they can get the assistance from their family members. As the birth rate declines and the population ages, the care function of large family structure gradually declines. In order to respond to an aging society, meet the huge long-term needs in the future and implement the policy goal of aging in place, the Executive Yuan passed the "Ten-Year Long-term Care Program 2.0" on September 29, 2016, and implement on January 1, 2017.

The home-based reablement services is a very important part in "Ten-Year Long-term Care Program 2.0", the main point of home-based reablement services is to provide services under the time-limited, person-centered, home-based intervention to residents who are suffer an accident or period of illness and need to face the threat of their functional decline. The services emphasize that the most meaningful activities of daily life for residents, goal-oriented and professional teamwork to help the residents with disability restore their ability to live independently and regain confidence as much as possible (Aspinal et al, 2016; Moe, Ingstad \& Brataas, 2017; Hjelle et al, 2017; Hjelle et al, 2018). In order to achieve this goal, the residents' physical and psychology condition, social participation abilities, support from the family members and the appropriateness of the living environment must be considered by the medical personnel. They should actively discuss with the residents with disability and their family members to realize the residents' life stories, remaining function and their actual needs. Subsequently, make effort to provide the appropriate treatment programs. 
Through the intervention by the medical personnel, the residents' most meaningful activities of daily life were be improved, the quality of life could be increased and the cost of care would be reduced. With the effective assist, the residents can do either to stay in home or return to the workplace and do what they want to do.

According to the "2025 Health and Welfare Policy White Paper" report by Ministry of Health and Welfare in Taiwan (2016), at present, there are still consist the problems of insufficient of medical personnel. As the demand for homebased reablement services increase year by year in Taiwan, which need to recruit a great number of medical personnel to participate. However, there are many negative factor reduce the intention of medical personnel to participate in the home-based reablement services. The medical personnel should provide the optimal professional services under the limited equipment and spaces, maybe suffer unpredictable crisis such as sexually harassment, violent treatment and so on. Therefore, how to attract and retain quality employees is very important. Past studies indicated that applied theory of planned behavior can actually understand the factors that influence the employee's intention to be hired, and as a reference for increasing employee recruitment (Ko et al, 2004; Fort, Pacaud \& Gilles, 2015; Greyling, 2016).

Ajzen (1985) indicated that individual's intention to engage in a behavior at a specific time and place and the behavioral intention will be determined by attitude, subjective norm and perceived behavioral control. Attitudes refers to the people from their passed experiments, cognition and emotion to evaluation whether to engage in a specific behavior were be benefit to them or not. Subjective norms refer to the impact degree of the opinions from others important people when the people engage in a specific behavior. Perceived behavioral control refers to the degree of ability when the people want to complete a certain behavior. The theory has been widely used as a research tool for various aspects of career choice, consumer behavior, scientific information, knowledge management, health care, and so on. The concept of corporate social responsibility(CSR)focus on the governments, corporations, institutions, or individuals who have engage in socially beneficial things or behaviors in addition to obey the norms of the legal and economic (Bondy, Moon \& Matten, 2012). This study, in addition to apply the theory of planned behavior to learn the influence of three determinants toward intention, we also focus on whether the medical personnel regards to participate in the home-based reablement services as a performance of social responsibility or not. In addition, we also explore the impact of CSR on intention.

This paper based on the theory of planned behavior and added one variable the CSR to investigate the relationship between CSR, attitude, subjective norms, perceived behavior control and intention. The questionnaires were distributed based on a purposive sampling method and collected in Yunlin, Chiayi City and Chiayi County from medical personnel who has participate in home-based reablement services. These areas were considered in this study since they are typical agricultural counties associated with a higher aging population rate $18.01 \%, 14.79 \%$ and $19.06 \%$, respectively in comparison to the average level in Taiwan $14.56 \%$ at the end of 2018. In particular, Chiayi County is the area with the highest proportion of elderly people in Taiwan. In order to encourage more and more medical personnel participate in home-based reablement services in the future, the empirical results in this study allow the government to understand what factors affect the intention of medical personnel to participate in the services. At the same time, as a reference for government to provide the optimal home-based reablement services plan and pre-employment training to increase their intention to participate in the home-based reablement service.

\section{Literature Review}

\subsection{Home-Based Reablement Services}

Home-based reablement services encourage residents to return to independent living after a period of lose health and help the residents with disability to remain in their own home as long as possible (Littlechild, Bowl \& Matka, 2010; Tuntland et al, 2015;Moe, Ingstad \& Brataas, 2017;Hjelle et al, 2018). According to the announcement of "The Professional Service Manual of Long-Term Care" by the Ministry of Health and Welfare in Taiwan (2018) and announcement of "Long-Term care service personnel training certification, continuing education and registration methods" by the Ministry of Health and Welfare in Taiwan (2017), the qualifications of executive home-based reablement services were the certification medical personnel include physicians, occupational therapists, physical therapists, speech therapists, registered professional nurse and other medical personnel. Relevant medical personnel must complete the training course of long-term care service before they starting to the provide services. The homebased reablement services' guidance content for the residents focus on daily activity design and arrangement, self-care training, living habits establishment and maintenance, emotional behavior counseling, physical function training and maintenance, and the training of using assist device. The guidance content for the caregivers mainly focus on the skill of the residents' daily functional care, supervised and training. Medical personnel should help to enhance the resident' independent motivation, increase the ability and confidence and reduce the need for care. Through the training by the medical personnel, the residents can be effectively implemented and participate in daily activities. Thus, their quality of life will be improved. 


\subsection{Corporate Social Responsibility}

Carroll $(1991,1999)$ indicated the evolution of CSR definitions will vary from time to time. The concept of corporate social responsibility evolves from the concept of social responsibility in the early stage of corporate only concern their own sustainable development, to today's corporate, in addition to considering their own financial and operational conditions, but also concerned with issues related to society and the natural environment. The conception of CSR contained four components. First, the economic responsibilities, to be profitable is the foundation. Second, the legal responsibilities is expected to obey the law because the law is society's baseline of right and wrong.

Third, the ethical responsibility, this is the obligation to avoid or minimize harm to stakeholders including employees, consumers, the environment, and others. Finally, the philanthropic responsibilities, being a good corporate citizen have to focus on contribute the resources to improve the quality of life for the community. More studies indicated that the employees' perceptions of CSR can influence their engagement, intentions to stay in the current organization (Yilmazdogan, Secilmis \& Cicek, 2015; Lin, et al, 2017; Low, Ong \& Tan, 2017) and job pursuit intention (Wang, 2013; Prihatiningsih, Syaebani \& Devina, 2017; Kumari \& Saini, 2018).

In recent years, in addition to provide career growth opportunities and work-life benefits, the perceptions of CSR has become one of strategy that is used to attract as many best talent to the organization (Leveson \& Joiner, 2014; Ersoy \& Aksehirli, 2015; Klimkiewicz \& Oltra, 2017). Some literatures indicated that to make employees work more productively and lower their turnover intention were effected by their perceptions of CSR (Ghosh \& Gurunathan, 2014; Yoo\& Chon, 2015; Yoon \& Lee, 2016). Dawkins et al, (2014) indicated whether the employees' perceptions of CSR impact the job choice or not will vary according to cultural differences. All the literatures in this subject gave us some knowledge to the effects of CSR on employees' job choice.

Rupp et al (2006) indicated that the employees' perceptions their employing organization's CSR efforts were impact their subsequent emotions, attitudes, and behaviors. Bashir, Hassan\& Cheema (2012) reported that the CSR activities of the organization will positively impacts employees' attitude towards their organizational trust, belongingness, job satisfaction and enhanced performance and then the employee swilling were be prolong to remain with the organization. Duarte et al (2014) indicated that the employees perceived the level of their corporate engagement in socially responsible practices were influences employees' attitudes and intentions towards their corporate.

In this study, the construct of CSR focused on explore perceptions CSR of the medical personnel and their regard that whether the medical personnel participation in the home-based reablement services is a manifestation of the professional taking social responsibility or not.

\subsection{Theory of Planned Behavior}

Theory of planned behavior is one of the famous behavioral psychology theory in social psychology, this theory evolved from the theory of reasoned action (Fishbein \& Ajzen, 1975). In addition to attitude and subjective norms of theory of reasoned action, the theory of planned behavior added the variable of perceived behavioral control due to individual behavior is usually not entirely self-willing. The theory of planned behavior states that individual's intention determine whether a person willing to perform a particular behavior or not and the intention will be determined by three constructs: attitude, subjective norms, and perceptual behavioral control (Ajzen, 1991). In this study, the construct of attitude focused on the medical personnel to assess the impact to themselves when they participate in home-based reablement services. The construct of subjective norm is to explore the influence of family members, relatives, friends and others on the decision-making of medical personnel to participate in home-based reablement services. The construct of perceived behavioral control focus on explores the time, physical and professional competence of medical personnel in their participation in the home-based reablement services and their ability to handle external resources. The construct of intention is to explore the willing of medical personnel sustain to eliminate all odds in order to participate in home-based reablement services, and even initiate their entrepreneurial intention.

\section{Methodology}

\subsection{Research Model and Hypotheses}




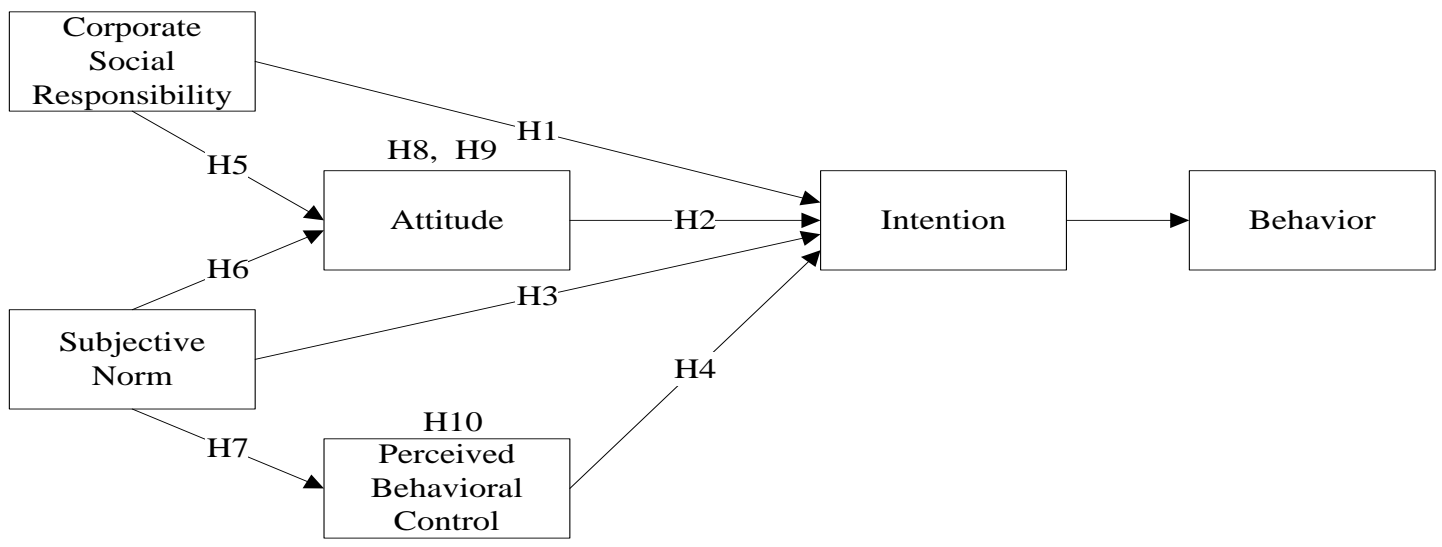

Figure 1 shows the research model considered.

According to the research model, ten hypotheses about the medical personnel to participate in home-based reablement services considered are listed as follows:

H1. CSR plays a positive role in affecting intention.

H2. Attitude plays a positive role in affecting intention.

H3. Subjective norm plays a positive role in affecting intention.

H4. Perceived behavioral control plays a positive role in affecting intention.

H5. CSR plays a positive role in affecting attitude.

H6. Subjective norm plays a positive role in affecting attitude.

H7. Subjective norm plays a positive role in affecting perceived behavioral control.

H8. Attitude has a mediation effect between CSR and intention.

H9. Attitude has a mediation effect between subjective norm and intention.

H10. Perceived behavioral control has a mediation effect between subjective norm and intention.

\subsection{Questionnaires Design}

The content validity refers to make sure the content of questionnaire is comprehensive, representative, appropriate, and does contain the meaning of the subject to be measured. In order to achieve this goal, the creation of the questionnaire was joint effort by two experienced occupational therapists, a director of nurse, an experienced physical therapy staff and a professional scholar. The questionnaire was built based on the concept of the relevant literature, it covers all the necessary items that should be addressed, and the questionnaire has content validity. Five constructs were contained in this questionnaire. Six items for construct of CSR were designed based on the works by and Sen, Bhattacharya and Korschun (2006), Cheng, Lee and Cheng (2014) and Hsieh, et al. (2016). Fifteen items for construct of attitude were designed based on the works by Blackwell, Miniard and Engel (2001), Ajzen (2006), Sen, Bhattacharya and Korschun (2006) and Jin, et al. (2011). Seven items for construct of subjective norm were designed based on the works by Ajzen (2006), Schiffman and Kanuk (2000),Jin, et al. (2011) and Dawkins et al. (2014). Fourteen items for construct of perceived behavior control were developed on the basis of the works by Taylor and Todd (1995) as well as Ajzen (2006), Jin, et al. (2011) and Dawkins et al. (2014). Nine items for construct of intention were developed on the basis of the works by Zeithaml, Berry and Parasuraman (1996), Ajzen (2006), Sen, Bhattacharya and Korschun (2006)and Jin, et al. (2011). Measure the overall perception of respondents. The five-point Likert-type scale was the most frequently used to anchor the level of respondents' agreement or disagreement with survey items from 1 to 5, where 1: Strongly Disagree; 2: Disagree; 3: neither Agree nor Disagree; 4: Agree; 5: Strongly Agree. In addition to these, eight items including gender, age, marital status, education level, profession, place of practice, year of practice and Transportation of going back and forth were designed to collect the demographic information.

In order to eliminate ambiguous and inappropriate phrasing and wording to minimize the misunderstanding and to ascertain the reliability and validity of the questionnaire, before the questionnaires were distributed a pilot study was conducted fromJune 1, 2018 to June 30, 2018.Total 50 medical personnel who has ever to participate in the home-based reablement services were recruited. According to the literature suggestion, if an item with standardized factor loading lower than 0.5, with value of corrected item to total correlation lower than 0.5 , and the value of Cronbach's alpha increases as it's not incorporated in measuring the corresponding construct, the item should be deleted. According to the results of analysis, no items in this pilot study should be deleted. 


\subsection{Data Collection}

In this study, purposive sampling was employed and the questionnaires were distributed from July 15 to August 30, 2018 to collect opinions of medical personnel who participated home-based reablement services in Yunlin, Chiayi City and Chiayi County. Altogether 150 questionnaires were distributed and 101 effective samples and agreements were collected, the rate of response was $67.3 \%$ in this study.

\section{Analysis and Discussion}

\subsection{Demographic Information}

Among 101 effective respondents, 28.7 percent were male and $49.5 \%$ were between 25-34 years old. 50.5 percent of the respondents were single. $85.1 \%$ of the respondents' educational level were bachelor's degree, 44.5 percent of the respondents were physical therapist, $94.1 \%$ of the respondents' place of practice were hospital, 30.7percent of the respondents' year of practice were below 1 year and55.14\% of the respondents' transportation of going back and forth were driving by self. The respondents' characteristics were be shown in Table 1.

Table 1: Sample demographic information

\begin{tabular}{|c|c|c|c|}
\hline Item & Answering Options & Frequency & Percent \\
\hline \multirow[t]{2}{*}{ Gender } & Male & 29 & 28.7 \\
\hline & Female & 72 & 71.3 \\
\hline \multirow[t]{4}{*}{ Age } & $\leqq 24$ years & 8 & 7.9 \\
\hline & 25-34years & 50 & 49.5 \\
\hline & 35-44years & 26 & 25.7 \\
\hline & $\geqq 45$ years & 17 & 16.8 \\
\hline \multirow[t]{3}{*}{ Marital status } & Single & 51 & 50.5 \\
\hline & Married without children & 14 & 13.9 \\
\hline & Married with children & 36 & 35.6 \\
\hline \multirow[t]{2}{*}{ Education level } & Bachelor's degree & 86 & 85.1 \\
\hline & Above bachelor's degree & 15 & 14.9 \\
\hline \multirow[t]{5}{*}{ Profession } & Physical therapists & 45 & 44.5 \\
\hline & Occupational therapists & 36 & 35.6 \\
\hline & Speech therapists & 4 & 4.0 \\
\hline & Registered professional nurse & 13 & 12.9 \\
\hline & Other & 3 & 3.0 \\
\hline \multirow[t]{3}{*}{ Place of practice } & Hospital & 95 & 94.1 \\
\hline & Clinic & 2 & 2.0 \\
\hline & Others & 4 & 3.9 \\
\hline \multirow[t]{5}{*}{ Year of practice } & $<1$ years & 31 & 30.7 \\
\hline & 1-3 (below) years & 26 & 25.7 \\
\hline & 3-5 (below)years & 14 & 13.9 \\
\hline & 5-7(below)years & 10 & 9.9 \\
\hline & $>7$ years & 20 & 19.8 \\
\hline \multirow{3}{*}{$\begin{array}{l}\text { Transportation of go } \\
\text { back and forth }\end{array}$} & Drive by self & 56 & 55.4 \\
\hline & Motorcycle & 42 & 41.6 \\
\hline & others & 3 & 3.0 \\
\hline
\end{tabular}

\subsection{Factor Analysis and Reliability Analysis}

Factor analysis is a statistical procedure that simplifies and summarizes a number of related variable data in order to grasp the cluster profile and strength of the variables. Factor analysis is mainly used to test the construct validity of the test, and it can also be used to select appropriate questionnaire items. Kaiser(1974) suggested that the Kaiser-MeyerOlkin (KMO) value should be greater than0.7 and Bartlett's test of sphericity being significant are the standard to exam the suitability of variable for factor analysis. In this study, the KMO value of CSR, attitude, subjective norm, perceived behavioral control and intention were $0.793,0.826,0.702,0.857$ and 0.888respectively. Each construct's KMO value is greater than0.7, and each construct's Bartlett's test of sphericity is significant, implying that they were suitable for factor analysis. The sum of variance explained for CSR, attitude, subjective norm, perceived behavioral control and intention were respectively given by $59.201 \%, 60.311 \%, 67.387 \%, 65.528 \%$ and $58.098 \%$. All the values of 
Cronbach's alpha were greater than 0.7, implying a high degree of internal consistency. The results of factor analysis and reliability analysis for each construct were shown in Table 2.

Table 2: Results of factor analysis and reliability analysis

\begin{tabular}{|c|c|c|c|c|c|}
\hline \multirow[b]{2}{*}{ Construct } & \multirow[b]{2}{*}{ Item } & \multicolumn{3}{|c|}{ Factor Analysis } & \multirow[b]{2}{*}{$\begin{array}{c}\text { Cronbach's } \\
\text { alpha }\end{array}$} \\
\hline & & \begin{tabular}{c|c|c|c|c|c|} 
Factor \\
Loading
\end{tabular} & \begin{tabular}{l|l} 
Eigen \\
Values
\end{tabular} & $\begin{array}{c}\% \text { of } \\
\text { Variance }\end{array}$ & \\
\hline \multirow{6}{*}{$\begin{array}{l}\text { Corporate } \\
\text { social } \\
\text { responsibility }\end{array}$} & $\begin{array}{l}\text { Ifeel that the participation of medical personnel in home-based reablement services is a } \\
\text { manifestation of the professional taking social responsibility. }\end{array}$ & 0.835 & \multirow{6}{*}{3.552} & \multirow{6}{*}{59.201} & \multirow{6}{*}{0.855} \\
\hline & $\begin{array}{l}\text { I think that whether the medical profession can be recognized by the public or not, depending on } \\
\text { the extent and scope of social responsibility taken by the profession. }\end{array}$ & 0.808 & & & \\
\hline & I am a person who cares about if the medical profession takes social responsibilities. & 0.798 & & & \\
\hline & $\begin{array}{l}\text { I feel that it is very important for the survival of the profession if the medical personnel can take } \\
\text { their social responsibility. }\end{array}$ & 0.780 & & & \\
\hline & I feel that medical personnel must pay more attention to social responsibility than to profit. & 0.725 & & & \\
\hline & For your own medical profession, it is important to invest in home-based reablement services. & 0.655 & & & \\
\hline \multirow{15}{*}{ Attitude } & Participating in the home-based reablement services can enhance my communication skills. & 0.748 & \multirow{15}{*}{9.047} & \multirow{15}{*}{60.311} & \multirow{15}{*}{0.876} \\
\hline & I feel that I am involved in the home-based reablement services can make my life very fulfilling. & 0.733 & & & \\
\hline & The improvement of residents' quality of life makes me felt a tremendous sense of achievement. & 0.729 & & & \\
\hline & $\begin{array}{l}\text { The improvement of residents' activities of daily living makes me felt a tremendous sense of } \\
\text { achievement. }\end{array}$ & 0.707 & & & \\
\hline & $\begin{array}{l}\text { The residents' and their family members have affirmed the effectiveness of receiving the home- } \\
\text { based reablement services, which makes me felt a tremendous sense of achievement. }\end{array}$ & 0.699 & & & \\
\hline & \begin{tabular}{|l} 
Participating in the home-based reablement services allows me to recognize diverse social values. \\
.
\end{tabular} & 0.693 & & & \\
\hline & I feel that I am happy to participate in the home-based reablement services. & 0.677 & & & \\
\hline & The working environment of the home-based reablement services is very challenging. & 0.665 & & & \\
\hline & Participating in the home-based reablement services can enhance my clinical experience. & 0.650 & & & \\
\hline & $\begin{array}{l}\text { The participation of medical personnel in the home-based reablement services can increase the } \\
\text { public's understanding of their profession. }\end{array}$ & 0.609 & & & \\
\hline & $\begin{array}{l}\text { Participating in the home-basedl reablement services can increase my income. } \\
\end{array}$ & 0.608 & & & \\
\hline & $\begin{array}{l}\text { The cost of the home-based reablement services paid by the government to medical personnel is } \\
\text { reasonable. }\end{array}$ & 0.457 & & & \\
\hline & $\begin{array}{l}\text { The process of paperwork required for medical staff to participate in the home-based reablement } \\
\text { services is simple. }\end{array}$ & 0.719 & & & \\
\hline & $\begin{array}{l}\text { Due to the proper planning of the management and project manager, the process of implementing } \\
\text { the home-based reablement services is very smooth. }\end{array}$ & 0.677 & & & \\
\hline & $\begin{array}{l}\text { Due to the complete planning of the long-term care management center, the process of } \\
\text { implementing the home-based reablement services is very smooth. }\end{array}$ & 0.661 & & & \\
\hline \multirow{7}{*}{$\begin{array}{l}\text { Subjective } \\
\text { norm }\end{array}$} & $\begin{array}{l}\text { Support from my relative members will affect my willingness to participate in the home-based } \\
\text { reablement services. }\end{array}$ & 0.916 & \multirow{7}{*}{4.717} & \multirow{7}{*}{67.387} & \multirow{7}{*}{0.770} \\
\hline & $\begin{array}{l}\begin{array}{l}\text { Support from my friends will affect my willingness to participate in the home-based reablement } \\
\text { services. }\end{array} \\
\text {. }\end{array}$ & 0.885 & & & \\
\hline & $\begin{array}{l}\text { Support from my family members will affect my willingness to participate in the home-based } \\
\text { reablement services. }\end{array}$ & 0.825 & & & \\
\hline & $\begin{array}{l}\begin{array}{l}\text { Discussions on the Internet will affect my willingness to participate in the home-based reablement } \\
\text { services. }\end{array} \\
\end{array}$ & 0.864 & & & \\
\hline & $\begin{array}{l}\text { TV news or program coverage will affect my willingness to participate in home-based reablement } \\
\text { services. }\end{array}$ & 0.800 & & & \\
\hline & $\begin{array}{l}\text { The government's long-term care service policy will affect my willingness to participate in home- } \\
\text { based reablement services. }\end{array}$ & 0.777 & & & \\
\hline & $\begin{array}{l}\text { I will participate in the home-based reablement services due to the recommendation or invitation } \\
\text { of other medical personnel. }\end{array}$ & 0.549 & & & \\
\hline \multirow{14}{*}{$\begin{array}{l}\text { Perceived } \\
\text { behavioral } \\
\text { control }\end{array}$} & I have ability of handle the crisis to complete the home-based reablement services. & 0.827 & \multirow{14}{*}{9.174} & \multirow{14}{*}{65.528} & \multirow{14}{*}{0.892} \\
\hline & I am able to work under pressure to complete the home-based reablement services. & 0.821 & & & \\
\hline & $\begin{array}{l}\text { I can adjust the strategy and method of implementing the home-based reablement services } \\
\text { according to the needs of the residents. }\end{array}$ & 0.777 & & & \\
\hline & I have enough affinity to be able to provide the home-based reablement services. & 0.763 & & & \\
\hline & I can provide instant education and consultation according to the needs of the residents. & 0.757 & & & \\
\hline & I have enough professional ability to complete the home-based reablement services. & 0.744 & & & \\
\hline & I can handle the transportation of go back and forth of the home-based reablement services. & 0.581 & & & \\
\hline & I have enough time to participate in the home-based reablement services. & 0.850 & & & \\
\hline & I have enough stamina to participate in the home-based reablement services. & 0.811 & & & \\
\hline & I can strike a balance between work and personal life. & 0.659 & & & \\
\hline & I can adjust the time for implementing the home-based reablement services with the residents. & 0.800 & & & \\
\hline & I can adjust the location of the home-based reablement services with the needs of the residents. & 0.657 & & & \\
\hline & I can instantly combine other related profession to provide the services that the residents need. & 0.566 & & & \\
\hline & $\begin{array}{l}\text { I can prepare the instruments or equipment used to practice the home-based reablement services } \\
\text { according to the needs of the residents. }\end{array}$ & 0.503 & & & \\
\hline & In the future, I am willing to continue to participate in the home-based reablement services. & 0.832 & & & \\
\hline & $\begin{array}{l}\text { If I receive information about activities related to the home-based reablement services, I will take } \\
\text { the initiative. }\end{array}$ & 0.825 & & & \\
\hline & In the future, I am willing to participate in various types of home-based reablement services. & 0.820 & & & \\
\hline & I am willing to sacrifice my rest time to participate in the home-based reablement services. & 0.767 & & & \\
\hline & $\begin{array}{l}\text { I am willing to recommend the benefits of participating in the home-based reablement services on } \\
\text { the Internet. }\end{array}$ & 0.760 & 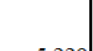 & 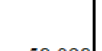 & \\
\hline Intention & $\begin{array}{l}\text { I am willing to recommend the benefits of receiving home-based reablement services to other } \\
\text { residents in need. }\end{array}$ & 0.720 & 5.22 & 58.098 & 0.902 \\
\hline & $\begin{array}{l}I \text { am willing to purchase the instruments or equipment needed to practice the home-based home- } \\
\text { based reablement services to improve the service efficiency. }\end{array}$ & 0.720 & & & \\
\hline & I am willing to become a full-time home-based reablement services medical personnel. & 0.718 & & & \\
\hline & $\begin{array}{l}\text { I am willing to recommend the benefits of participating in the home-based reablement services to } \\
\text { other medical personnel. }\end{array}$ & 0.682 & & & \\
\hline
\end{tabular}


The highest factors loading item in the construct of CSR is "I feel that the medical personnel participation in the homebased reablement services is a manifestation of the professional taking social responsibility". "Participating in the home-based reablement services can enhance my communication skills" is a highest factor loading item in the construct of attitude. The highest factors loading item in the construct of subjective norm is "Support from my relative members will affect my willingness to participate in the home-based reablement services. "I have ability of handle the crisis to complete the home-based reablement services" is the highest factors loading item in the construct of perceived behavioral control. The highest factors loading item in the construct of intention is "In the future, I am willing to continue to participate in the home-based reablement services".

\subsection{Regression Analysis}

From table 3, the result of step 1 to step 4 reveal that the standardized regression coefficients of CSR, attitude, subjective norm and perceived behavioral control to intention were respectively given by $0.663,0.511,0.681$ and 0.731 . All the results were statistically significant and therefore the hypotheses H1, H2, H3 and H4 were not rejected. The perceived behavioral control were be the highest degree of influence on the four constructs to intention. Compare the results given in step1,step 3, step5 and step8 in table 3, CSR to intention, attitude to intention and CSR to attitude were respectively given by $0.663,0.681$ and 0.567 , All the results were statistically significant and the standardized regression coefficient of CSR to intention decreased from 0.663 to $0.408(\mathrm{p}<0.05)$, after adding attitude in regression model. Following the Baron and Kenny (1986), attitude has a partial mediation effect on the relationship between CSR and intention. Hence, the hypothesis H5 and H8 was not rejected. Compare the results given in step 2, step 3, step 6 and step 9 in table 3, subjective norm to intention, attitude to intention and subjective norm to attitude were respectively given by $0.551,0.681$ and 0.411 , All the results were statistically significant and the coefficient of subjective norm declined from 0.511 to 0.278 ( $\mathrm{p}<0.05$ ), after adding attitude in regression model. So, the hypothesis H6 and H9 were not rejected, we conclude that attitude has a partial mediation effect between subjective norm and the intention. Compare the results given in step 2, step 4, step 7 and step10 in table 3, subjective norm to intention, perceived behavioral control to intention and subjective norm to perceived behavioral control were respectively given by0.511, 0.731 and 0.371 , All the results were statistically significant and the coefficient of subjective norm declined from 0.511 to 0.278 ( $\mathrm{p}<0.05)$, after adding perceived behavioral control in regression model. So, the hypothesis $\mathrm{H} 7$ and $\mathrm{H} 10$ were not rejected, we conclude that perceived behavioral control has a partial mediation effect between subjective norm and the intention.

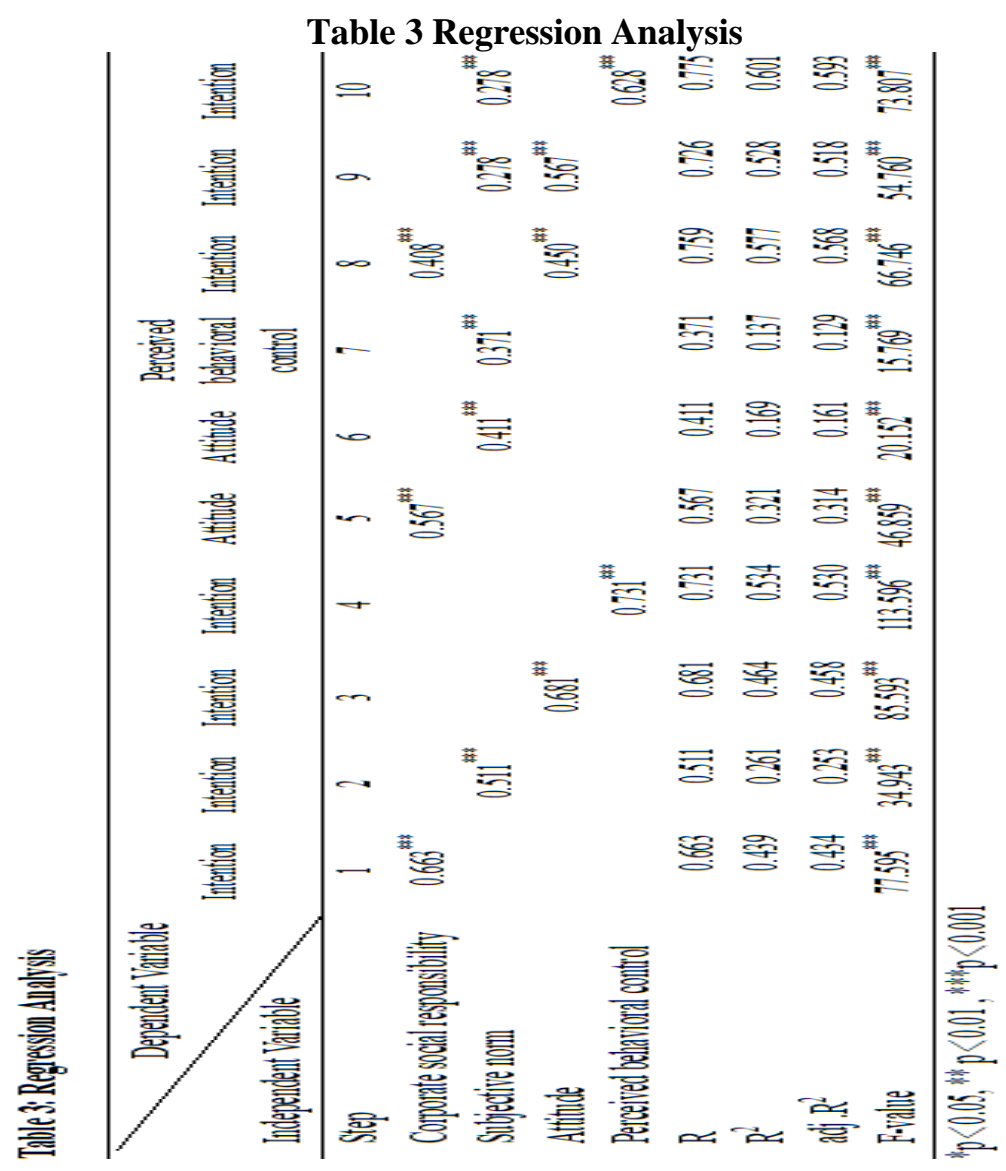




\section{Conclusions}

In view of increasing needs of the home-based reablement services in Taiwan, our findings provide important clinical implications for the home-based reablement services. Successful home-based reablement services require care managers of long-term care management center, medical personnel and residents can work together to complete. This study offer us some knowledge about the affecting factors of medical personnel to participate in the home-based reablement services. The medical personnel care more about whether they have enough time, ability and work well under pressure when they implemented the home-based reablement services or not. Besides, strengthening medical personnel perception of CSR, promoting their clinical experience, simplifying paperwork, increasing their sense of accomplishment and support from others will affect intention of medical personnel to participate in the home-based reablement services. In this study, based on the cross-sectional design and the sample data was gathered within Yunlin, Chiayi City and Chiayi County in Taiwan, so the results cannot be broadly applied to other areas. In order to explore whether there are alterations between different years and different regions or not, future research should consider to gather the longitudinal data from different regions.

\section{Acknowledgements:}

The authors would like to thank all the participants. We thank an experienced nurse Kuei-Jung Pai, two experienced occupational therapist Man-Li Lin, Yen-Ling Lin and an experienced physical therapist Min-Cheng Wu for their professional suggestions.

\section{References}

Ajzen, I. (1985). From intention to action: A theory of planned behavior. In J. Kuhl, \& J. Beckmann (Eds.), Actioncontrol: From cognition to behavior (pp. 11-39). New York: Springer-Verlag.

Ajzen, I. (1991). The theory of planned behavior. Organizational Behavior and Human Decision Processes, 50, 179211.

Azjen, I. (2006). Constructing a theory of planned behavior questionnaire. [Online] Available: https://www.researchgate.net/publication/235913732 (April 1, 2018).

Aspinal, F., \& Glasby, J., \& Rostgaard, T., \& Tuntland, H., \& Weatendorp, R. G. J. (2016).New horizons: Reablement - supporting older people towards independence. Age and Ageing, 45, 574-578. DOI: 10.1093/ageing/afw094

Baron, R. M., \& Kenny, D. A. (1986). The moderator-mediator variable distinction in socialpsychological research: Conceptual, strategic and statistical considerations. Journal of Personality and Social Psychology, 51(6), 11731182.

Bashir, R., Hassan, A., \& Cheema, F.-E.-A. (2012). Impact of corporate social responsibility activities over the employees of the organizations: An exploratory study. Journal of Management and Social Sciences, 8(2), 1121.

Blackwell, R. D., Miniard, P.W., \&Engel J. F. (2001). Consumer behavior (9th ed.). Australia: SouthWestern/Thomson Learning.

Bondy, K., Moon, J., \& Matten, D. (2012). An institution of corporate social responsibility (CSR) in multi-national corporations (MNCs): Form and implications. Journal of Business Ethics, 111, 281-299.

Caroll, A. B. 1991. The pyramid of corporate social responsibility: Toward the moral management of organizational stakeholders. Business Horizons, 34(4), $39-48$.

Carroll, A. B. (1999).Corporate Social Responsibility- Evolution of a Definitional Construct. Business\& Society, 38(3), 268-295.

Cheng, J. H., Lee, C. M.,\& Chen, H. P.(2014).Assessing Inter-organizational Performance in Supply Chain-Corporate Social Responsibility as a Mediator. Asia Pacific Management Review, 19(1), 61-79.

Dawkins, C.E., Jamali, D., Karam, C., Lin, L. \& Zhao, J. (2014). Corporate Social Responsibility and Job Choice Intentions: A Cross-Cultural Analysis. Business \& Society, 1-35. DOI: 10.1177/0007650314564783

Department of Household Registration, Ministry of the Interior, Taiwan (2019), 2018 Statistics of internal affairs. [Online] Available: https://www.ris.gov.tw/app/portal/346 (January31, 2019).

Dawkins, C.E., Jamali, D., Karam, C., Lin, L. and Zhao, J. (2014). Corporate social responsibility and job choice intentions: a cross-cultural analysis. Business \& Society, 10.1177/0007650314564783.

Duarte, A. P., Gomes, D. R., \&Gonçalves das Neves, J. (2014). Finding the jigsaw piece for our jigsaw puzzle with corporate social responsibility: The impact of CSR on prospective applicants' responses. Management Research: The Journal of the Iberoamerican Academy of Management, 12(3), 240-258. 
Ersoy, I., \&Aksehirli, Z. (2015). Effects of perceptions of corporate social responsibility on employer attractiveness. Research Journal of Business and Management, 2(4), 507-518.

Executive Yuan, Taiwan (2016). Ten-Year Long-term Care Program 2.0. [Online] Available: https://www.ey.gov.tw/Upload.aspx?Upload=/RelFile/.../1051219 長照 2.0 核定本.pdf. (May 11, 2018).

Fishbein, M., \&Ajzen, I. (1975). Belief, attitude, intention and behavior: An introduction to theory and research. Reading, MA: Addison-Wesley.

Fort, I., Pacaud, C., \& Gilles, P.Y. (2015). Job search intention, theory of planned behavior, personality and job search experience. International Journal for Educational and Vocational Guidance, 15(1), 57-74.

Ghosh, D., \& Gurunathan, L. (2014).Linking Perceived Corporate Social Responsibility and Intention to Quit: The Mediating Role of Job Embeddedness. Vision: The Journal of Business Perspective, 18(3) 175-183.

Greyling, E (2016). The applicability of the Theory of Planned Behaviour to choosing a career as a rural physician in South Africa. The Degree of Ph.D. with specialization in Human Resource Management, University of Pretoria.

Hjelle, K. M., Tuntland, H., Førland, O., \& Alvsvåg, H. (2017). Driving forces for home-based reablement; a qualitative study of older adults' experiences. Health Soc Care Community, 25(5), 1581-1589. DOI: 10.1111/hsc.12324.

Hjelle, K. M., Skutle, O., Alvsvåg, H, \& Førland, O. (2018). Reablement teams' roles: a qualitative study of interdisciplinary teams' experiences. Journal of Multidisciplinary Healthcare, 11, 305-316.

Hsieh, H. C.,Chiu,H. C., Hsieh, Y. H., Ho, P. S., Li-Chin Chen, L. C. \&Chang, W. C. (2016). The Perceptions and Expectations Toward the Social Responsibility of Hospitals and Organizational. The Journal of Nursing Research, 24(3), 249-261.

Jin, L., Lunhua Mao, L., Zhang, J., \& Walker, M. (2011). Impact of green stadium initiatives on donor intentions toward an intercollegiate athletic programme. International Journal of Sport Management \& Marketing, 10, 124-141.

Kaiser, H. F. (1974). An index of factorial simplicity. Psychometrik, 39(1), 31-36.

Klimkiewicz, K., \& Oltra, V. (2017) Does CSR Enhance Employer Attractiveness? The Role of Millennial Job Seekers' Attitudes. Corp. Soc. Responsib. Environ. Mgmt., 24: 449-463. DOI: 10.1002/csr.1419.

Ko, N. Y., Feng, M. C., Chiu, D. Y., Wu, M. H., Feng, J. Y., \& Pan, S. M. (2004).Applying theory of planned behavior to predict nurses' intention and volunteering to care for SARS patients in southern Taiwan. Kaohsiung J Med Sci, 20(8), 389-98. DOI: 10.1016/S1607-551X(09)70175-5

Kumari, S., \& Saini, G. K. (2018). Do instrumental and symbolic factors interact in influencing employer attractiveness and job pursuit intention? Career Development International, 23(4), 444-462. DOI: 10.1108/CDI-03-20180069

Leveson, L., and Joiner, T.A. (2014). Exploring corporate social responsibility values of millennial job-seeking students. Education and Training, 56(1), 21-34. DOI: 10.1108/ET-11-2012-0121

Lin, C.P., Lin, C.P., Liu, M.L., \& Liu, M.L. (2017). Examining the effects of corporate social responsibility and ethical leadership on turnover intention. Personnel Review, 46(3), 526-550. DOI: 10.1108/PR-11-2015-0293

Littlechild, R., Bowl, R., \& Matka1, E. (2010).An Independence at Home Service: The Potential and the Pitfalls for Occupational Therapy Services. British Journal of Occupational Therapy, 73(6), 242-250.

Low, M. P., Ong, S. F., \& Tan, P.M.( 2017).Would internal corporate social responsibility make a difference in professional service industry employees' turnover intention? A two-stage approach using PLS-SEM. Global Business and Management Research: An International Journal, 9 (1), 24-41.

Ministry of Health and Welfare, Taiwan (2016). 2025 Health and Welfare Policy White Paper. [Online] Available: http://tagv.mohw.gov.tw/TAGVResources/upload/Resources/2017/4/2025 衛生福利政策白皮書.pdf (May 20, 2018).

Ministry of Health and Welfare, Taiwan (2017). Long-Term care service personnel training certification, continuing education and registration methods. [Online] Available: https://www.mohw.gov.tw/cp-18-29134-1.html (May 20, 2018).

Ministry of Health and Welfare, Taiwan (2018). The Professional Service Manual of Long-Term Care. [Online] Available: https://www.health.ntpc.gov.tw/archive/health_ntpc/6/file/長照專業服務手冊.pdf (May 20, 2018).

Moe, A., Ingstad, K., \& Brataas, H. V. (2017). Patient influence in home-based reablement for older persons: qualitative research. BMC Health Services Research, 17(1), 736, 1-10. DOI: 10.1186/s12913-017-2715-0.

Prihatiningsih, W., Syaebani, M. I., \& Devina, M. (2017). Impact Analysis On Corporate Social Responsibility Towards Job Pursuit Intention With Socio-Environmental Consciousness As A Moderating Variable: Case Study Of Undergraduate Students At Universitas Benefit. BENEFIT Jurnal Manajemen dan Bisnis, 115-124. DOI: 10.23917/benefit.v2i2.5476 
Rupp, D. E., Ganapathi, J., Aguilera, R. V., \& Williams, C. A. 2006. Employee reactions to corporate social responsibility: An organizational justice framework. Journal of Organizational Behavior, 27: 537-543.

Schiffman, L. G., \& Kanuk, L. L. (2000). Consumer behavior (7th ed.). Upper Saddler River, NJ: Prentice Hall.

Sen, S., Bhattacharya, C. B., \& Korschun, D. (2006).The Role of Corporate Social

Responsibility in Strengthening Multiple Stakeholder Relationships: A Field Experiment. Journal of the Academy of Marketing Science, 34(2), 158-166. DOI: 10.1177/0092070305284978

Taylor, S., \&Todd, P. (1995). Understanding information technology usage: A test of competing models. Information Systems Research, 6(2), 144-176.

Tuntland, H., Aaslund, M., Espehaug, B., Førland, O., \&Kjeken, I. (2015). Reablement in community-dwelling older adults: A randomised controlled trial. BMC Geriatr, 15(1):1-11.

Wang, R.T. (2013): Modeling Corporate Social Performance and Job Pursuit Intention: MediatingMechanisms of Corporate Reputation and Job Advancement Prospects. Journal of Business Ethics,117(3): 569-582.

Y1lmazdogan, O. C., Secilmis, C., \& Cicek, D. (2015).The effect of Corporate Social Responsibility (CSR) perception on tourism students' intention to work in sector, Science Direct, Procedia Economics and Finance 23, 1340 1346. DOI: 10.1016/S2212-5671(15)00321-4

Yoo, J. M., \& Chon, M. L. (2015).The Effect of CSR on Employees' Turnover Intention: Comparative Study on Harmful and Non-Harmful Industry. Indian Journal of Science and Technology, 8(21), DOI: $10.17485 / \mathrm{ijst} / 2015 / \mathrm{v} 8 \mathrm{i} 21 / 79157$

Yoon, J., \& Lee, S. (2016). What Makes Employees Zealous Supporters of Their Firm's CSR Initiative? The Role of Employees' Perceptions of Their Firm's CSR Authenticity. Advances in Group Processes, 33, 93 - 126.

Zeithaml, V. A., Berry, L. L., \&Parasuraman, A. (1996). The behavioral consequences of service quality. Journal of Marketing, 60(2), 31-46. 